\title{
The lack of paid sick leave as a barrier to cancer screening and medical care-seeking: results from the National Health Interview Survey
}

\author{
Lucy A Peipins $^{1 *}$, Ashwini Soman², Zahava Berkowitz ${ }^{1}$ and Mary C White
}

\begin{abstract}
Background: Preventive health care services, such as cancer screening can be particularly vulnerable to a lack of paid leave from work since care is not being sought for illness or symptoms. We first describe the prevalence of paid sick leave by broad occupational categories and then examine the association between access to paid sick leave and cancer testing and medical care-seeking in the U.S. workforce.
\end{abstract}

Methods: Data from the 2008 National Health Interview survey were analyzed by using paid sick leave status and other health-related factors to describe the proportion of U.S. workers undergoing mammography, Pap testing, endoscopy, fecal occult blood test (FOBT), and medical-care seeking.

Results: More than 48 million individuals (38\%) in an estimated U.S. working population of 127 million did not have paid sick leave in 2008. The percentage of workers who underwent mammography, Pap test, endoscopy at recommended intervals, had seen a doctor during the previous 12 months or had at least one visit to a health care provider during the previous 12 months was significantly higher among those with paid sick leave compared with those without sick leave after controlling for sociodemographic and health-care-related factors.

Conclusions: Lack of paid sick leave appears to be a potential barrier to obtaining preventive medical care and is a societal benefit that is potentially amenable to change.

Keywords: Cancer screening, Pap test, Mammography, FOBT, Colonoscopy, Paid sick leave, Health benefits

\section{Background}

Paid sick leave is paid time taken off from work by individuals to attend to their own or their family member's illness or other medical needs without loss of pay or job loss. Paid sick leave in the Unites States is a provision by the employer and not an insurance option. Currently in the United States there are no federal legal requirements for paid sick leave [1]. The Federal Family and Medical Leave Act (FMLA) provides up to 12 weeks of unpaid leave for specified medical conditions for employees of companies with 50 or more employees [2], but FMLA does not apply to workers who need time off for routine or preventive medical care. Both San Francisco and Washington, DC have passed legislation guaranteeing paid sick leave to workers in their cities. In addition,

\footnotetext{
* Correspondence: LBP6@CDC.GOV

'Epidemiology and Applied Research Branch, DCPC, CDC, 4770 Buford

Highway, NE, Mailstop K-55, Atlanta, GA 30341-3717, USA

Full list of author information is available at the end of the article
}

measures providing sick leave have passed in Milwaukee, WI and Seattle, WA but have not yet been enacted [3].

Concern about the lack of paid sick leave was heightened during the 2009 H1N1 influenza outbreak when the Centers for Disease Control and Prevention recommended that workers remain at home if they were sick with flu-like symptoms to control the spread of infection [4], and emergency legislation guaranteeing temporary sick leave was introduced in the House of Representatives [5]. In addition to the potential for reducing the spread of infection, the ability to take sick leave is likely to have an effect on a much wider range of health conditions and care-seeking both for workers and their families.

Preventive health services, including cancer screening, can be particularly vulnerable to a lack of paid leave since, by definition, preventive care is not sought for illness or symptoms. The United States Preventive Services Task Force (USPSTF) and the American Cancer Society recommend regular screening for the prevention of

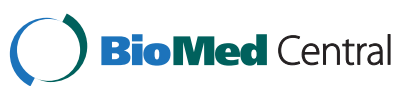


breast, colorectal and cervical cancers for early detection or removal of precancerous lesions [6,7]. However, screening rates for breast, cervical, and colorectal cancer in the US remain lower for people with lower income and education, without health insurance, and Hispanic ethnicity [7-10]. The USPSTF also recommends screening for high blood pressure and further screening for diabetes for those with high blood pressure [11]. This screening is typically part of a medical care visit.

Although the lack of health insurance coverage and access to preventive care have been broadly examined, [12-15] we are not aware of research to assess the effect of paid sick leave on the use of cancer screening services. In 2008, the Task Force on Community Preventive Services completed a systematic review of research on client-directed interventions to increase cancer screening [16]. The research examined did not address paid sick leave but did include other efforts to reduce out-ofpocket expenses. The Task Force concluded that there was sufficient evidence to show that reducing out-ofpocket costs increased the use of mammography but the evidence was judged insufficient to determine the effectiveness of similar interventions for cervical or colorectal cancer screenings. The aims of this analysis are to (1) describe the prevalence of paid sick leave by broad occupational categories and other occupationally-related groupings and (2) examine the association between access to paid sick leave and cancer testing and medical care-seeking in the U.S. working population.

\section{Methods}

\section{Study population}

We used data from the 2008 National Health Interview Survey (NHIS), a multi-purpose health survey of a probability-based sample of the U.S. civilian noninstitutionalized population conducted by the CDC's National Center for Health Statistics (NCHS). The majority of the interviews were conducted in person by trained interviewers from the U.S. Census Bureau, and 25\% were completed by telephone. The interviewed sample for 2008 consisted of 74,236 persons in 29,421 families from 28,790 households yielding a household response rate of approximately $85 \%$, a conditional sample adult response rate of $74 \%$, and a final adult sample size of 11,826 with a sample adult response rate of 63\% [17].

The focus of this analysis was currently employed adults who were 18 years of age and older. This group included adults currently working for pay at a job or business in the prior week or adults working at a job or business but not at work in the prior week. We excluded workers who were self-employed, working without pay, working in a family business, looking for work, or not working (Figure 1).

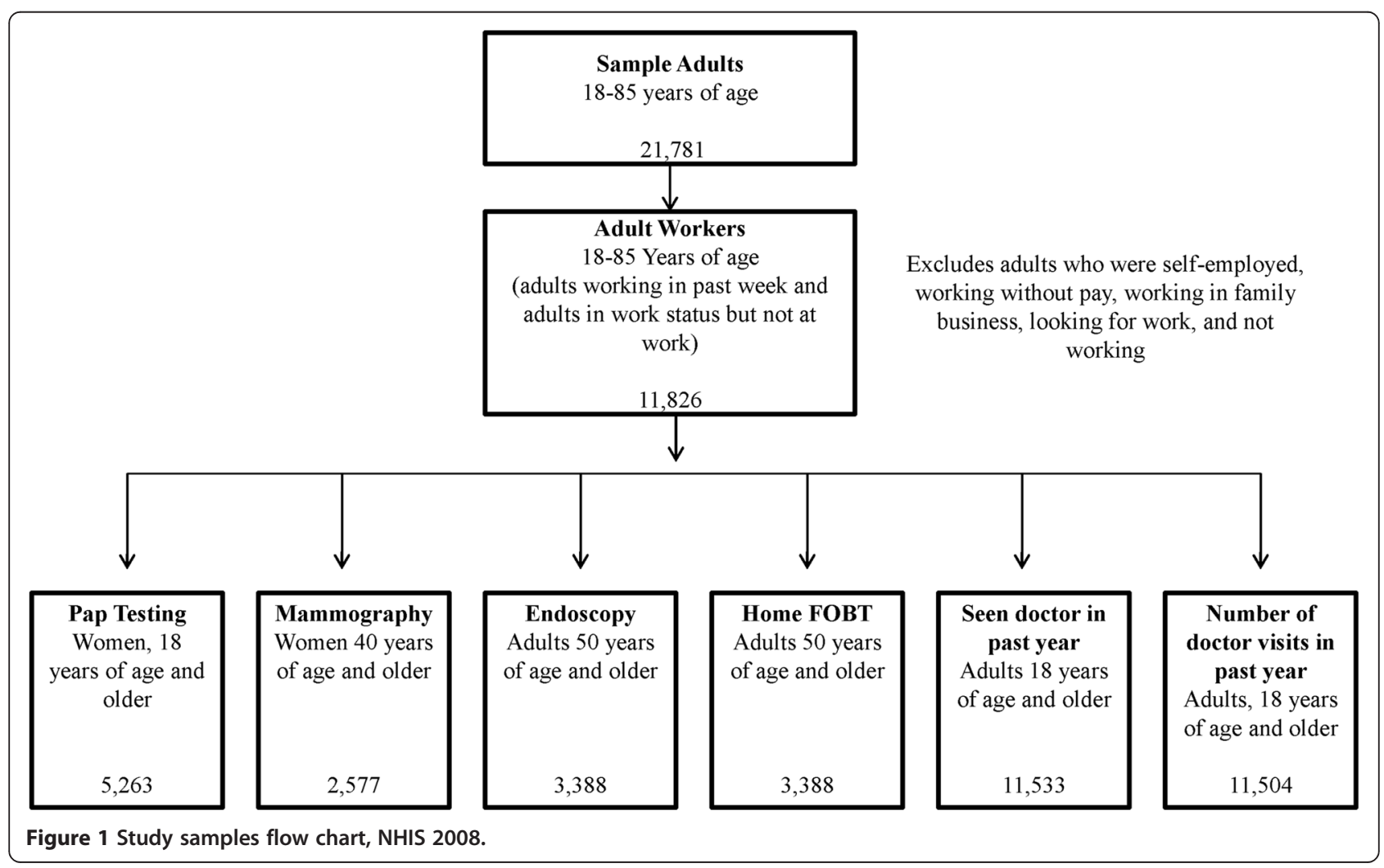




\section{Occupational characteristics}

Respondents were asked about the kind of work they did (occupation) and the current job or work situation (employed by a private company or federal, state or local government). Two-digit codes based on the Standard Occupational Classification [18] were assigned to each verbatim response by NCHS [19]. We collapsed the occupations into 5 general categories that included management occupations (codes 01-04), professional/ technical occupations (codes 05-31), service occupations (codes 32-52), sales and office administrative support occupations (codes 53-64), and a general production category that included construction, production, transportation and maintenance occupations as well as farming, forestry and fishing occupations (codes 65-93).

Information was obtained on the number of people who worked at the respondent's current job location. The possible response categories of 1-9 employees, 10-24 employees, 25-49 employees, 50-99 employees, 100-249 employees, 250-499 employees, 500-999 employees and 1,000 or more employees were collapsed into 4 groups (Table 1). Currently working respondents reported how many years they had worked at a main job or business. Years at work were categorized as $0-1,2-5,6-15$ and 16 or more. Respondents answered 'yes' or 'no' to the question, "Do you have paid sick leave on this main job or business?"

\section{Cancer tests and medical care seeking}

Respondents were asked if they had ever had a colorectal exam, the type of exam, when they had the exam and the reasons for the exam. We classified respondents who reported having had a colonoscopy during the past 10 years or sigmoidoscopy during the past 5 years for any reason as having had an endoscopy within recommended screening guidelines. Although FOBT is currently recommended with sigmoidoscopy [6], the use of sigmoidoscopy represents only a small fraction of endoscopic screening procedures, and this recommendation in 2008 may not be reflected in the data used for this analysis. We used the definition of screening by sigmoidoscopy during the past 5 years to permit comparisons with other published estimates. In addition, respondents were

Table 1 Percent of U.S. workforce with paid sick leave by occupational characteristics, NHIS, 2008

\begin{tabular}{|c|c|c|c|c|c|}
\hline Characteristics & NHIS sample & $\begin{array}{l}\text { Estimated \# of } \\
\text { U.S. workers }\end{array}$ & $\begin{array}{l}\% \text { with paid } \\
\text { sick leave* }\end{array}$ & $95 \% \mathrm{Cl}$ & $\begin{array}{l}\text { Estimated \# of workers } \\
\text { with no sick leave }\end{array}$ \\
\hline All workers & 11,826 & $127,067,000$ & 61.9 & $60.7-63.1$ & $48,352,000$ \\
\hline \multicolumn{6}{|l|}{ Occupation } \\
\hline Management & 874 & $10,120,800$ & 81.1 & $77.5-84.2$ & $1,915,200$ \\
\hline Professional/Technical & 3,281 & $35,349,700$ & 79.0 & $77.1-80.7$ & $7,442,100$ \\
\hline Services & 1,997 & $21,028,300$ & 41.2 & $38.3-44.1$ & $12,373,000$ \\
\hline Sales/Office & 2,873 & $30,406,100$ & 64.3 & $62.3-66.3$ & $10,843,800$ \\
\hline Production** & 2,423 & $27,492,200$ & 53.9 & 51.4-56.4 & $14,818,500$ \\
\hline \multicolumn{6}{|l|}{ Class of worker } \\
\hline Private & 9,577 & $104,319,000$ & 57.0 & $55.7-58.3$ & $44,858,100$ \\
\hline Federal & 306 & $3,063,100$ & 91.5 & 86.6-94.7 & 260,200 \\
\hline State & 858 & $8,967,500$ & 81.5 & $77.5-85.0$ & $1,655,200$ \\
\hline Local & 975 & $10,717,600$ & 85.3 & $82.2-87.9$ & $1,578,500$ \\
\hline \multicolumn{6}{|l|}{ Years on the job } \\
\hline $0-1$ & 3,250 & $35,737,500$ & 45.1 & $42.9-47.3$ & $19,632,200$ \\
\hline $2-5$ & 3,542 & $38,651,600$ & 60.3 & $58.1-62.4$ & $15,353,000$ \\
\hline $6-15$ & 3,115 & $32,914,500$ & 71.9 & 69.8-73.9 & $9,236,480$ \\
\hline $16+$ & 1,704 & $18,662,600$ & 79.4 & 76.8-81.7 & $3,854,130$ \\
\hline \multicolumn{6}{|l|}{ Number of employees } \\
\hline$<10$ & 2,073 & $22,388,100$ & 41.6 & $39.0-44.1$ & $13,086,000$ \\
\hline $10-49$ & 3,084 & $34,408,900$ & 53.1 & 50.8-55.4 & $16,136,000$ \\
\hline $50-249$ & 2,878 & $31,806,300$ & 69.4 & $67.0-71.7$ & $9,737,850$ \\
\hline $250+$ & 2,485 & $32,820,100$ & 79.4 & $77.4-81.3$ & $6,760,420$ \\
\hline
\end{tabular}

* Percentages are weighted to the population of workers.

** Production category includes Production, Agricultural, Forest and Fishery workers.

$\mathrm{Cl}$ indicates confidence interval.

Totals in categories may not sum to all worker totals because of missing and unknown values. 
asked if they had ever used an FOBT home kit, and the date of their most recent test. Respondents, who had never had this test or had not had one during the prior year as recommended by national guidelines, were classified as not having the test. Women were asked if they had had a mammography and a Pap smear or Pap test, when they had the tests and the reasons for the test. Women who reported having had a mammogram during the prior 2 years or a Pap test during the prior 3 years as part of a routine exam were classified as having had a mammogram or Pap test respectively [6].

Respondents were asked if they had seen or talked to a general practice, internal medicine or family doctor during the prior 12 months and how many times during the prior 12 months they had seen a doctor or other health care professional in a doctor's office, clinic or location other than a hospital, emergency room, or dental office or spoken to one by telephone. For this analysis we dichotomized the number of doctor visits as no visits versus one or more visits during the prior 12 months.

\section{Age groups and gender}

For analyses of cancer testing, we included working women 40 years and older in the analysis of mammography. During the time of this survey, recommendations for mammography included women from age 40 to 49 years [20]. All adult working women (18 years of age or older) were included in analyses of Pap testing. Colorectal cancer analyses (endoscopy and FOBT) focused on adults 50 years of age or older. Analyses of the outcomes of those individuals who had seen or spoken with a doctor and the number of visits included all working adults 18 years of age and older. Figure 1 presents a chart of population sub-groups for analyses. We assumed that most adults who were healthy enough to work could potentially benefit from early cancer detection, regardless of age, and therefore we did not apply an upper age limit for the use of any cancer screening test.

\section{Other covariates}

All variables were self-reported. These included age (classified by 10 year age groups), education (less than high school, high school or GED, some college and college graduates), race/ethnicity (Hispanic, non-Hispanic white, non-Hispanic black, and non-Hispanic other), poverty ratio ( $<100 \%, 100 \%$ to $<200 \%, 200 \%$ to $<400 \%, 400 \%$ or more), insurance status (private, public only, private and public, not covered and unknown), usual source of medical care (yes, no, and only emergency room care) and marital status (never married, married/partnered, and widowed/divorced). Missing data for income was imputed by using multiple imputation [17].

\section{Statistical analysis}

We used descriptive statistics to examine the distribution of occupational characteristics of the U.S. workforce with and without paid sick leave. In addition, we used the chi-square test to examine the association of having paid sick leave with the uptake of various cancer tests, the number of physician visits and whether members of this population have been seen by a doctor during the prior year. We used six multivariate logistic regression models that show the association between sick leave status and various socio-demographic characteristics with each of the cancer tests, number of physician visits, and whether members saw a doctor during the prior year. To enable easy interpretation of the models' results, we computed and presented adjusted percentages (predicted margins), which are derived from the logistic regression model [21]. Overall associations were assessed with the Wald F statistic, and differences between categories within each adjusted variable were tested using general linear contrasts of the percentages.

To generalize the results to the population, each respondent was assigned a sampling weight. The weights accounted for selection probability and non-response. A P-value of less than 0.05 was considered statistically significant. We considered an estimate to be unstable and recommend caution in interpretation if the relative standard error, (calculated as [standard error/estimated percentage] x 100), was more than $30 \%$. All statistical analyses were performed by using SAS 9.2 with SUDAAN release 10 (Research Triangle Institute, Research Triangle Park, NC) to adjust for the complex sampling design of the NHIS.

\section{Results}

More than 48 million currently employed U.S. workers reported having no paid sick leave at their main job or business (Table 1). The percentage of workers with paid sick leave varied by class of worker, years on the job and number of employees at the respondent's location of work. Service occupations had the lowest percentage of workers with paid sick leave (41\%), and management workers had the highest percentage (81\%) among occupational categories. The percentage of workers with paid sick leave was lower among private vs. all levels of the public sector. As years on the job and number of employees in a work location increased, the percentage of workers with paid sick leave increased.

Table 2 presents the relationship between having paid sick leave and cancer testing and medical care seeking. The percentage of workers who underwent mammography, Pap test, endoscopy at recommended intervals, had seen a doctor during the prior 12 months or had at least one visit to a health care provider during the prior 12 months was significantly higher among those with 
Table 2 Percentages and $95 \%$ Cls of U.S. workers undergoing cancer tests and medical care-seeking by paid sick leave, NHIS, 2008

\begin{tabular}{|c|c|c|c|c|c|c|}
\hline \multirow{3}{*}{ Cancer test } & \multirow{3}{*}{$\mathrm{n}$} & \multicolumn{4}{|c|}{ Paid Sick Leave } & \multirow{3}{*}{$p^{*}$} \\
\hline & & \multicolumn{2}{|c|}{ Has sick leave } & \multicolumn{2}{|c|}{$\begin{array}{l}\text { Doesn't have } \\
\text { sick leave }\end{array}$} & \\
\hline & & $\%$ & $95 \% \mathrm{Cl}$ & $\%$ & $95 \% \mathrm{Cl}$ & \\
\hline Mammography & 2,555 & 83.6 & $81.5-85.5$ & 75.8 & $72.1-79.2$ & $<0.00$ \\
\hline Pap Test & 5,218 & 89.9 & $88.7-91.0$ & 86.4 & $84.5-88.1$ & $<0.00$ \\
\hline Endoscopy & 3,224 & 52.7 & $50.1-55.3$ & 43.1 & $39.7-46.5$ & $<0.00$ \\
\hline Home FOBT & 3,208 & 9.2 & $7.8-10.8$ & 9.7 & $7.9-11.9$ & 0.68 \\
\hline \# physician visits & 11,504 & 84.0 & $82.8-85.2$ & 72.0 & 70.3-73.7 & $<0.00$ \\
\hline \multicolumn{7}{|l|}{ in past year } \\
\hline Seen doctor in & 11,533 & 69.1 & 67.6-70.4 & 57.9 & $56.1-59.8$ & $<0.00$ \\
\hline \multicolumn{7}{|l|}{ past year } \\
\hline \multicolumn{7}{|c|}{$\begin{array}{l}\text { FOBT, fecal occult blood test; } \mathrm{Cl} \text {, confidence interval; } \\
\text { Mammography within past } 2 \text { years, women age }>39 \text {. } \\
\text { Endoscopy for adult workers within past } 5 \text { years for flexible sigmoido } \\
10 \text { years for colonoscopy. } \\
\text { Home FOBT for adult workers within past year age }>49 \text {. } \\
\text { \# physician visits and seen doctor in past } 12 \text { months for all workers. } \\
\text { p }^{*} \text { values are based on an chi square test for association. }\end{array}$} \\
\hline
\end{tabular}

paid sick leave as compared with those without sick leave. The percentage of workers who reported having an FOBT within the prior year was less than $10 \%$ and did not vary by sick leave status.

After adjusting for sociodemographic and health related characteristics (Table 3), the associations between paid sick leave and mammography, Pap test and endoscopy remained statistically significant. The unadjusted and adjusted proportions of cancer tests by sick leave were quite similar. Working women 40 years of age and older with sick leave were more likely to have had a mammogram within the prior 2 years $(83.3 \%$; $95 \% \mathrm{CI}$, 81.2-85.2) than those without sick leave $(77.0 \%$; $95 \%$ CI, 72.9-79.9). No associations found between age, education, poverty ratio, health insurance status, race/ethnicity and mammography use. However, associations still remained for marital status and having a usual source for medical care. Married or partnered workers were more likely to have had a mammography than those who were widowed or divorced $(83.2 \%$ vs $77.1 \%$, $\mathrm{p}<0.01$ ) adjusting for covariates. Workers without a usual source of care were less likely to report a mammogram (57.1\%; 95\% CI, 47.5-66.2) than workers who had a usual source of care (82.7\%; 95\% CI, 81.0-84.3).

Among working women, we saw a small but statistically significant difference in Pap test reporting by paid sick leave status $(91.9 \%$ vs. $89 \%, P<0.04)$. A significant difference in reported Pap testing was also seen for age with the highest proportion of Pap tests being reported by the youngest workers (aged 18-29 years) when compared with all other age groups $(\mathrm{p}<0.001)$. Widowed or divorced workers were less likely to report having had a
Pap test $(88.2 \%)$ than married or partnered workers (92.0\%), $(P<0.01)$. In addition, workers with a usual source of care $(93.5 \%$; 95\% CI, 92.6-94.3) were more likely to have reported a Pap test compared with workers without a usual source of care $(68.8 \%$; 95\% CI, 63.873.5). No associations with Pap testing were seen for education, poverty ratio, health insurance, or race/ ethnicity.

A similar pattern was observed for endoscopy reporting. A larger proportion of workers with paid sick leave reported having had an endoscopy $(52.5 \%$; $95 \%$ CI, 49.955.0) than workers who lacked sick leave (43.5\%; $95 \%$ CI 40.1-47.1). Higher proportions of workers aged 6069 years or older reported endoscopy compared with those aged $50-59$ years $(P<0.001)$. Married workers were significantly more likely to have had an endoscopy (51.7\%; 95\% CI, 49.0-54.3) than workers who were widowed or divorced (44.8\%; 95\% CI, 41.4-48.2). Having a usual source of care was significantly associated with reporting an endoscopy $(P<0.001)$. No association was found between education, poverty ratio, health insurance or race/ethnicity and endoscopy. Only age and marital status were statistically and significantly associated with home FOBT. Workers aged 50-59 years were less likely to have reported an FOBT home test than workers aged 60-69 years $(P<0.001)$ or workers 70 years of age and older $(P=0.02)$. Contrary to results for other cancer testing, widowed or divorced workers were more likely to report a home FOBT test $(P=0.01)$. Finally, workers with a usual source of care were more likely than to report a home FOBT than workers without a usual source of care $(10.0 \%$; $95 \% \mathrm{CI}, 8.9-11.4$ vs. $2.0 \%$; $95 \% \mathrm{CI}$, 0.75-5.2).

Table 4 presents results for medical-care-seeking among working men and women. The overall proportion of workers reporting having seen a doctor during the prior year in any setting was higher than the proportion of workers who had at least one physician visit in an office or clinic setting. Only sick leave, age, and marital status significantly predicted having seen a doctor during the prior year or having had at least one physician visit. Workers with sick leave were more likely to have had at least one physician visit in an office or clinic (68.4\%; $95 \%$ CI, 66.9-69.8) than those without sick leave (59.2\%; 95\% CI 57.3-61.0). A similar relationship was observed for workers seeking medical care in any setting including an emergency room. As expected, older workers (6069 years of age and 70 years of age or older) were more likely to report having seen a physician at least once in a clinic or office than workers $50-59$ years of age $(83.4 \%$; 95\% CI, 80.4-86.1 and 83.2\%; 95\%CI 76.4-88.4 vs. 72.1\%; 95\% CI, 69.8-74.4). This relationship was also observed for having seen a doctor during the prior year in any setting. Widowed or divorced workers reported 
Table 3 Adjusted population percentages and 95\% Cls of U.S. workers undergoing cancer tests, NHIS, 2008

\begin{tabular}{|c|c|c|c|c|c|c|c|c|c|c|c|c|}
\hline \multirow[t]{2}{*}{ Characteristics } & \multicolumn{3}{|c|}{$\begin{array}{l}\text { Mammography } \\
(n=2,545)\end{array}$} & \multicolumn{3}{|c|}{$\begin{array}{l}\text { Pap Test } \\
(n=4,505)\end{array}$} & \multicolumn{3}{|c|}{ Endoscopy $(n=3,210)$} & \multicolumn{3}{|c|}{$\begin{array}{l}\text { Home FOBT } \\
(n=3,194)\end{array}$} \\
\hline & $\mathrm{PM}^{*}$ & $95 \% \mathrm{Cl}$ & $P^{* *}$ & $\mathrm{PM}^{*}$ & $95 \% \mathrm{Cl}$ & $P^{* *}$ & $\mathrm{PM}^{*}$ & $95 \% \mathrm{Cl}$ & $P^{* *}$ & $\mathrm{PM}^{*}$ & $95 \% \mathrm{Cl}$ & $P^{* *}$ \\
\hline \multicolumn{13}{|l|}{ Sick leave } \\
\hline Yes & 83.3 & $81.2-85.2$ & $<0.001$ & 91.9 & $90.6-93.0$ & $<0.04$ & 52.5 & $49.9-55.0$ & $<0.001$ & 9.3 & $8.0-10.9$ & 0.83 \\
\hline No & 77.0 & 72.9-79.9 & & 89.9 & 88.1-91.4 & & 43.5 & $40.1-47.1$ & & 9.6 & 7.7-11.8 & \\
\hline \multicolumn{13}{|l|}{ Age years } \\
\hline $18-29$ & - & & 0.29 & 97.0 & $95.5-98.0$ & $<0.001$ & - & & $<0.001$ & - & & $<0.001$ \\
\hline $30-39$ & - & & & 91.6 & $89.7-93.1$ & & - & & & - & & \\
\hline $40-49$ & 79.6 & $76.6-82.3$ & & 88.4 & $86.2-90.3$ & & - & & & - & & \\
\hline $50-59$ & 81.5 & $78.7-83.1$ & & 87.3 & $84.3-89.8$ & & 46.0 & $43.5-48.6$ & & 7.8 & $6.6-9.2$ & \\
\hline $60-69$ & 84.4 & $81.2-88.0$ & & 83.1 & $78.2-87.0$ & & 56.9 & $53.0-60.6$ & & 12.7 & $10.4-15.3$ & \\
\hline $70+$ & 84.0 & $74.2-90.4$ & & 70.1 & $55.5-81.5$ & & 60.7 & $52.7-68.2$ & & 13.7 & $9.5-19.4$ & \\
\hline \multicolumn{13}{|l|}{ Race/ethnicity } \\
\hline Hispanic & 80.7 & $77.0-84.0$ & 0.48 & 90.4 & 88.0-92.3 & 0.90 & 49.2 & 44.9-53.6 & 0.79 & 9.4 & $7.3-12.2$ & 0.69 \\
\hline Non-Hispanic White & 80.8 & 78.3-83.1 & & 92.2 & 90.9-93.4 & & 50.5 & $47.6-53.4$ & & 9.6 & $8.1-11.3$ & \\
\hline Non-Hispanic Black & 81.2 & $76.1-85.4$ & & 88.0 & 84.6-90.7 & & 46.5 & $40.9-52.2$ & & 7.9 & $5.5-11.3$ & \\
\hline Non-Hispanic Asian & 87.3 & $80.3-92.1$ & & 90.9 & $86.7-93.8$ & & 51.3 & $42.9-59.6$ & & 10.4 & $6.0-17.4$ & \\
\hline Non-Hispanic Other & 81.9 & $64.6-91.9$ & & 94.1 & $85.5-97.7$ & & 48.2 & $31.9-64.8$ & & 14.8 & $6.6-30.0$ & \\
\hline \multicolumn{13}{|l|}{ Marital status } \\
\hline Never married & 77.7 & $71.6-82.8$ & 0.00 & 91.5 & $89.1-93.5$ & 0.01 & 42.5 & $36.0-49.2$ & 0.002 & 9.1 & $6.1-13.3$ & 0.02 \\
\hline Married/partnered & 83.2 & $80.9-85.3$ & & 92.0 & 90.6-93.1 & & 51.7 & $49.0-54.3$ & & 8.5 & $7.2-10.1$ & \\
\hline Widowed/Divorced & 77.1 & $74.0-80.0$ & & 88.2 & 85.8-90.2 & & 44.8 & $41.4-48.2$ & & 12.2 & $10.2-14.7$ & \\
\hline \multicolumn{13}{|l|}{ Education } \\
\hline$<$ high school & 80.5 & $77.5-83.2$ & 0.08 & 91.8 & 90.0-93.3 & 0.70 & 49.8 & 46.1-53.5 & 0.51 & 10.2 & 8.3-12.6 & 0.80 \\
\hline High school/GED & 79.8 & 75.7-83.4 & & 90.9 & 88.7-92.7 & & 50.3 & 46.1-54.5 & & 8.9 & $6.7-11.8$ & \\
\hline Some college & 84.3 & $80.5-87.6$ & & 91.4 & $89.1-93.2$ & & 49.4 & $44.9-53.9$ & & 8.6 & $6.5-11.3$ & \\
\hline College graduate & 77.8 & $72.2-82.5$ & & 89.7 & 87.1-91.9 & & 46.0 & 41.0-51.2 & & 8.9 & $6.5-12.0$ & \\
\hline missing & 86.5 & $80.5-91.0$ & & 91.4 & 88.0-94.0 & & 53.6 & $46.9-60.2$ & & 10.4 & $7.2-14.9$ & \\
\hline \multicolumn{13}{|l|}{ Poverty ratio } \\
\hline$<100 \%$ & 84.0 & 78.3-88.4 & 0.20 & 92.1 & 88.8-94.5 & 0.71 & 43.3 & $37.3-49.4$ & 0.12 & 6.7 & 4.4-10.1 & 0.14 \\
\hline $100 \%$ to $<200 \%$ & 76.7 & 71.6-81.1 & & 89.9 & $87.3-92.0$ & & 52.1 & $46.5-57.6$ & & 11.5 & $8.5-15.3$ & \\
\hline $200 \%$ to $<400 \%$ & 82.2 & 78.9-85.1 & & 91.3 & 89.3-93.0 & & 52.0 & 47.7-56.3 & & 10.4 & $8.1-13.4$ & \\
\hline $400 \%$ or more & 82.4 & $79.1-85.3$ & & 90.8 & 89.0-92.3 & & 49.8 & 46.1-53.4 & & 9.7 & $7.6-12.2$ & \\
\hline Unknown & 80.5 & $76.5-84.1$ & & 91.7 & $89.5-93.5$ & & 48.2 & $43.5-52.9$ & & 7.9 & $5.9-10.6$ & \\
\hline \multicolumn{13}{|l|}{ Health insurance } \\
\hline Private & 80.4 & $76.9-83.5$ & 0.25 & 90.4 & $88.3-92.1$ & 0.2 & 48.2 & $44.6-51.8$ & 0.44 & 9.9 & $7.9-12.2$ & 0.76 \\
\hline Public only & 79.4 & 75.1-83.2 & & 91.8 & 89.6-93.6 & & 51.6 & 47.1-55.9 & & 8.9 & $7.0-11.2$ & \\
\hline Public and Private & 84.4 & $81.4-87.0$ & & 90.7 & 88.6-92.4 & & 51.1 & 47.1-55.1 & & 10.1 & $7.8-12.9$ & \\
\hline Not covered & 80.0 & $75.6-83.9$ & & 91.9 & $89.6-93.7$ & & 46.7 & $41.8-51.6$ & & 8.2 & $6.0-11.1$ & \\
\hline Unknown & 78.1 & $50.6-92.5$ & & 97.3 & 91.9-99.1 & & 51.0 & $32.5-69.2$ & & 6.9 & $2.0-20.8$ & $* * *$ \\
\hline Usual Source of Care & & & $<0.001$ & & & $<0.001$ & & & $<0.001$ & & & $<0.001$ \\
\hline Yes & 82.7 & 81.0-84.3 & & 93.5 & 92.6-94.3 & & 51.7 & 49.5-53.9 & & 10.0 & $8.9-11.4$ & \\
\hline No & 57.1 & $47.5-66.2$ & & 68.8 & 63.8-73.5 & & 20.6 & $15.5-26.8$ & & 2.0 & $0.75-5.2$ & $* * *$ \\
\hline
\end{tabular}

FOBT, fecal occult blood test; $\mathrm{Cl}$, confidence interval;

Mammography in past 2 years, women age $>39$ home FOBT, adult workers in past year, age $>49$ screening endoscopy, adult workers within past 5 years for

flexible sigmoidoscopy or 10 years for colonoscopy.

*PM, predicted marginals from multivariate logistic models including all variables in Table 3.

$\mathrm{p}^{* *}$ values are based on an overall Wald $\mathrm{F}$ Chi Square test for association from multivariate logistic regression models.

${ }^{* * *}$ relative standard error is greater than $30 \%$, interpret estimate with caution. 
Table 4 Adjusted population percentages and 95\% Cls of U.S. workers visiting a physician, NHIS 2008

\begin{tabular}{|c|c|c|c|c|c|c|}
\hline \multirow[t]{2}{*}{ Characteristics } & \multicolumn{3}{|c|}{$\begin{array}{l}\text { \# Physician Visits ( } n=11,504) \\
\text { (in clinic or office) }\end{array}$} & \multicolumn{3}{|c|}{$\begin{array}{l}\text { Seen doctor in past year ( } n=11,533) \\
\text { (in any setting including ER) }\end{array}$} \\
\hline & $\mathrm{PM}^{*}$ & $95 \% \mathrm{Cl}$ & $P^{* *}$ & $\mathrm{PM}^{*}$ & $95 \% \mathrm{Cl}$ & $P^{* *}$ \\
\hline \multicolumn{7}{|l|}{ Sick leave } \\
\hline Yes & 68.4 & $66.9-69.8$ & $<0.001$ & 84.6 & 82.4-84.9 & $<0.001$ \\
\hline No & 59.2 & $57.3-61.0$ & & 72.8 & 71.2-74.4 & \\
\hline \multicolumn{7}{|l|}{ Age years } \\
\hline $18-29$ & 55.9 & $53.1-58.7$ & $<0.001$ & 75.0 & $72.5-77.4$ & $<0.001$ \\
\hline $30-39$ & 59.9 & $57.7-62.0$ & & 74.8 & 72.9-76.6 & \\
\hline $40-49$ & 66.7 & $64.5-69.0$ & & 80.1 & $78.1-82.0$ & \\
\hline $50-59$ & 72.1 & $69.8-74.4$ & & 84.2 & $82.2-86.1$ & \\
\hline $60-69$ & 83.5 & $80.4-86.1$ & & 93.4 & $91.5-94.9$ & \\
\hline $70+$ & 83.2 & $76.4-88.4$ & & 93.5 & $89.2-96.2$ & \\
\hline \multicolumn{7}{|l|}{ Race/ethnicity } \\
\hline Hispanic & 63.8 & 61.4-66.1 & 0.54 & 79.2 & 77.1-81.2 & 0.99 \\
\hline Non-Hispanic White & 65.1 & $63.5-66.7$ & & 79.5 & $78.2-80.2$ & \\
\hline Non-Hispanic Black & 64.2 & $61.3-67.0$ & & 79.4 & $76.8-81.8$ & \\
\hline Non-Hispanic Asian & 67.9 & $63.4-72.0$ & & 79.9 & $76.1-83.2$ & \\
\hline Non-Hispanic Other & 63.4 & $51.7-73.6$ & & 77.9 & $66.9-86.1$ & \\
\hline \multicolumn{7}{|l|}{ Marital status } \\
\hline Never married & 64.0 & $61.8-66.2$ & 0.01 & 78.1 & $76.0-80.0$ & $<0.001$ \\
\hline Married/partnered & 65.8 & $64.2-67.4$ & & 80.1 & $79.3-82.0$ & \\
\hline Widowed/Divorced & 61.4 & $58.5-64.2$ & & 75.9 & $73.4-78.2$ & \\
\hline Education & & & 0.48 & & & 0.21 \\
\hline$<$ high school & 66.2 & $64.2-68.2$ & & 80.9 & $79.2-82.5$ & \\
\hline High school/GED & 64.3 & $62.0-66.6$ & & 79.2 & $77.1-81.2$ & \\
\hline Some college & 64.4 & $61.9-66.8$ & & 79.1 & $76.8-81.3$ & \\
\hline College graduate & 63.5 & $60.9-66.0$ & & 78.5 & $76.2-80.6$ & \\
\hline missing & 64.7 & $60.9-68.4$ & & 77.7 & $74.2-80.8$ & \\
\hline \multicolumn{7}{|l|}{ Poverty ratio } \\
\hline$<100 \%$ & 64.1 & $61.1-67.1$ & 0.91 & 80.6 & 77.6-83.4 & 0.11 \\
\hline $100 \%$ to $<200 \%$ & 65.6 & $62.8-68.4$ & & 80.0 & $77.6-82.2$ & \\
\hline $200 \%$ to $<400 \%$ & 64.2 & $62.0-66.3$ & & 80.8 & $78.9-82.6$ & \\
\hline $400 \%$ or more & 65.1 & $63.0-67.0$ & & 77.7 & $76.0-79.4$ & \\
\hline Unknown & 65.1 & $62.5-67.6$ & & 79.2 & $77.0-81.3$ & \\
\hline \multicolumn{7}{|l|}{ Health insurance } \\
\hline Private & 66.2 & $64.3-68.0$ & 0.26 & 80.6 & $78.6-82.4$ & 0.12 \\
\hline Public only & 63.6 & $61.3-65.8$ & & 79.2 & $77.1-81.2$ & \\
\hline Public and Private & 64.2 & $62.1-66.3$ & & 79.1 & $76.3-79.9$ & \\
\hline Not covered & 65.5 & $62.6-68.2$ & & 79.5 & $77.1-81.8$ & \\
\hline Unknown & 58.6 & $49.2-67.2$ & & 86.1 & 78.8-91.1 & \\
\hline
\end{tabular}

*PM, predicted marginal from logistic regression model using all variables in Table 4.

$\mathrm{p}^{* *}$ values are based on an overall Wald Chi Square test for association from multivariate logistic regression models.

ER is Emergency Room.

the lowest proportions of medical care-seeking as compared with married or partnered workers. No significant relationship was seen for education, poverty level, race/ ethnicity or poverty level and medical care seeking.

\section{Conclusions}

Out of an estimated U.S. working population of 127 million in 2008, more than 48 million (38\%) lack paid sick leave. Approximately $60 \%$ of private-sector workers and 
more than $80 \%$ of state and local government workers had paid sick leave. Our analysis shows that it was workers in service or production occupations, those in the private sector, and those in smaller firms with fewer years on the job who were less likely to report having sick leave. Furthermore, our results from this nationally representative sample demonstrate that sick leave could be a significant barrier to cancer testing and medical care seeking.

Both unadjusted and adjusted proportion of workers undergoing mammography, Pap test, endoscopy and medical care-seeking were significantly higher for those with paid sick leave than those who lacked paid sick leave. It was only for home FOBT that we did not see an association with paid sick leave. Compared with endoscopy which requires contact with a physician and time away from work, testing for blood in the stool with an FOBT test kit is performed at home. In addition, the proportion reporting home FOBT was much smaller than the proportion reporting endoscopy.

Screening behavior is affected by a myriad of factors that vary within different populations. We adjusted for sociodemographic factors that have been shown to be barriers or facilitators of cancer testing or medical careseeking in the United States. Race/ethnicity, education, age, household income, marital status, usual source of care and health-care coverage have been associated with colorectal cancer screening [10,12,13], mammography $[9,13]$, and Pap testing [13] in population-based surveys, including the NHIS and a random sample of Medicare beneficiaries [22]. Our study population, which included only U.S. working men and women, is likely to differ in important ways from the U.S. population as a whole or the Medicare population. Consistent with previous research, we also reported a significant contribution of age and marital status to models of cancer screening or medical care-seeking as outcomes, but saw no significant differences in cancer screening by health insurance status or poverty. This could be due to a population of working men and women having less variability in insurance status and poverty level than a general population. Among working adults, lack of paid sick leave may pose a more significant barrier to cancer testing and medical care-seeking than lack of insurance or poverty.

This analysis has some limitations. For example, data are based on self-report and respondents may have incorrectly reported their screening use and the timing of that screening. A recent meta-analysis of the accuracy of self-reports of cancer screening concluded that national survey data overestimate the prevalence of screening and mask disparities by race and ethnicity because of differences in reporting accuracy [23]. In addition, the survey seeks information only on paid sick leave and no other leave such as paid personal or annual leave, and the survey does not capture any restrictions on the use of sick leave for preventive health care. Workers may have personal leave or vacation leave but may not consider or report these categories as paid sick leave. Thus, we may have underestimated the proportion of workers with leave that could be counted for cancer screening. However, our estimates of worker's access to paid sick leave were similar to the Bureau of Labor Statistics (BLS) estimates of $61 \%$ for private-industry workers and $89 \%$ of state and local workers during 2008 [24]. Differences are primarily due to differences in survey design. Whereas the NHIS is a survey of randomly chosen individuals from households who are representative of the noninstitutionalized U.S. population, the BLS estimates are obtained from the National Compensation Survey, an employer-based survey representing a random selection of establishments chosen from state unemployment insurance records [25].

Barriers to cancer screening and routine medical careseeking involve a complex web of individual, community, health care system and societal characteristics. In the working population, a person's occupation is the source of his or her income and medical insurance coverage, and of other benefits such as paid sick leave, worker's compensation, paid vacation, and retirement benefits [26]. In short, a person's occupation is the source of some of the most critical elements determining their health and well-being. And in the United States, access to these benefits is largely determined by the type of occupation. The percentage of workers with access to paid sick leave is lowest among service workers, workers in construction and maintenance, transportation workers, and part-time workers, and highest among managers and professional workers. This occupational structure disproportionately affects women who are more likely to be low-wage and part-time workers [27].

Lack of paid sick leave can be considered within the category of out-of-pocket costs for medical care. Those without sick leave who take work time off for preventive services may lose pay. High deductibles and other forms of cost sharing have been associated with underuse of preventive services $[28,29]$, specifically colorectal cancer screening [30] and mammography [31,32]. Lack of paid sick leave appears to be a potential barrier to obtaining needed medical care and a societal benefit that is potentially amenable to change.

\section{Abbreviations}

NHIS: National Health Interview Survey; Cl: Confidence interval; FOBT: Fecal occult blood test; NCHS: National Center for Health Statistics; FMLA: Family and Medical Leave Act; USPSTF: United States Preventive Services Task Force.

\section{Competing interests}

The authors declare that they have no competing interests. 


\section{Author details}

${ }^{1}$ Epidemiology and Applied Research Branch, DCPC, CDC, 4770 Buford Highway, NE, Mailstop K-55, Atlanta, GA 30341-3717, USA. ²Northrop Grumman, 3375 Northeast Expressway, Atlanta, GA 30341, USA

\section{Authors' contributions}

$L A P, Z B, A S$ and MCW designed the study. AS and ZB conducted the statistical analyses. LAP, AS, ZB and MCW contributed to the interpretation of the data. LAP drafted the manuscript with contributions from $A S, Z B$ and MCW. LAP, AS, ZB and MCW read and approved the final manuscript. The findings and conclusions in this report are those of the authors and do not necessarily represent the official position of the Centers for Disease Control and Prevention.

Received: 25 January 2012 Accepted: 12 July 2012

Published: 12 July 2012

\section{References}

1. U.S. Department of Labor: Work Hours. Sick leave. Http://www.dol.gov/dol/ topic/workhours/sickleave.htm. Accessed May 11, 2011.

2. U.S. Bureau of Labor Statistics: Selected Paid Leave Benefits, Table 6, National Compensation Survey, March 2010:: Economic News Release; Http:// datablsgov/cgi-bin/print/pl/news/release/egs2t06htm. Accessed August 31, 2010

3. Thompson $L(E d)$ : The Seattle Times. Seattle, WA: Seattle Times Company; 2011. http://seattletimes.nwsource.com/html/localnews/ 2015009895_sickleave10m.html.

4. Centers for Disease Control and Prevention: CDC Recommendations for Amount of Time Persons With Influenza-Like IIInesses Should Be Away From Others. October 23, 2009. http://www.cdc.gov/h1n1flu/guidance/exclusion. htm.

5. Committee on Education and the Workforce: House Democrats Introduce H1N1 Flu Emergency Sick-Leave Bill. Press release November 3, 2009. http://democrats.edworkforce.house.gov/newsroom/2009/11/housedemocrats-introduce-h1n1.shtml Accessed May 11, 2011.

6. U.S. Preventive Services Task Force (USPSTF): Guide to Clinical preventive Services 2010-2011. Washington, DC: Agency for Healthcare Research and Quality; http://www.ahrq.gov/clinic/pocketgd1011/pocketgd1011.pdf. Accessed May 9, 2011.

7. Smith RA, Cokkinides V, Brooks D, Saslow D, Shah M, Brawley OW: Cancer screening in the United States, 2011. CA Cancer J Clin 2011, 61(1):8-30.

8. Klabunde CN, Cronin KA, Breen N, Waldron WR, Ambs AH, Nadel MR: Trends in colorectal cancer test use among vulnerable populations in the United States. Cancer Epidemiol Biomark Prev 2011, 20(8):1611-1621.

9. Richardson L, Rim S, Plescia M: Vital signs: breast cancer screening among women aged 50-74 years---United States, 2008. Morb Mortal Wkly Rep (MMWR) 2010, 59(July 6, 2010):6-9.

10. Richardson L, Tai E, Rim S, Joseph D, Plescia M: Vital signs: colorectal cancer screening, incidence, and mortality---United States, 2002-2010. Morb Mortal Wkly Rep (MMWR) 2011, 59:1-6. July 5, 2011/60(Early Release).

11. U.S. Preventive Services Task Force (USPSTF): Screening for high blood pressure: U.S. Preventive Services Task Force reaffirmation recommendation statement. Ann Intern Med 2007, 147(11):783-786.

12. Shapiro JA, Seeff LC, Thompson TD, Nadel MR, Klabunde CN, Vernon SW: Colorectal cancer test use from the 2005 National Health Interview Survey. Cancer Epidemiol Biomark Prev 2008, 17(7):1623-1630.

13. Swan J, Breen N, Graubard BI, McNeel TS, Blackman D, Tangka FK, Ballard-Barbash R: Data and trends in cancer screening in the United States. Cancer 2010, 116(20):4872-4881.

14. Vidal L, LeBlanc WG, McCollister KE, Arheart KL, Chung-Bridges K, Christ S, Caban-Martinez AJ, Lewis JE, Lee DJ, Clark J 3rd, et al: Cancer screening in US workers. Am J Public Health 2009, 99(1):59-65.

15. Ward E, Halpern M, Schrag N, Cokkinides V, DeSantis C, Bandi P, Siegel R, Stewart A, Jemal A: Association of insurance with cancer care utilization and outcomes. CA Cancer J Clin 2008, 58(1):9-31.

16. Baron RC, Rimer BK, Coates RJ, Kerner J, Kalra GP, Melillo S, Habarta N, Wilson KM, Chattopadhyay S, Leeks K: Client-directed interventions to increase community access to breast, cervical, and colorectal cancer screening: a systematic review. Am J Prev Med 2008,

35(1, Supplement):S56-S66.
17. Adams P, Heyman K, Vickerie J: Summary health statistics for the U.S. population: National Health Interview Survey, 2008. National Center for Health Statistics. Vital Health Stat 2009, 10(243):1-113.

18. U.S. Department of Labor: Bureau of Labor Statistics. Standard occupational classification. 2011, http://www.bls.gov/soc/. Accessed August 15, 2011

19. National Center for Health Statistics (NCHS): 2008 National health interview survey (NHIS) public use data release: NHIS survey description. Atlanta, GA: Centers for Disease Control and Prevention, U.S. Department of Health and Human Services; 2009.

20. US Preventive Services Task Force: Screening for breast cancer: United States Preventive Services Task Force Recommendation Statement. Ann Intern Med 2002, 137(Part 1):344-346.

21. Groubard Bl, Korn EL: Predictive margins with survey data. Biometrics 1999, 55:652-659.

22. White A, Vernon SW, Franzini L, Du XL: Racial and ethnic disparities in colorectal cancer screening persisted despite expansion of Medicare's screening reimbursement. Cancer Epidemiol Biomark Prev 2011, 20(5):811-817.

23. Rauscher GH, Johnson TP, Cho Yl, Walk JA: Accuracy of self-reported cancer-screening histories: a meta-analysis. Cancer Epidemiol Biomark Prev 2008, 17(4):748-757.

24. U.S. Bureau of Labor Statistics: Paid sick leave in the United States. Program Perspect 2010, 2(2):1-4. Available at http://www.bls.gov/opubs/ perspectives/program_perspectives_vol2_issue2.pdf. Accessed August 15, 2011

25. U.S. Bureau of Labor Statistics: National Compensation Survey. http://www. bls.gov/eci/. Accessed August 15, 2011.

26. Lipscomb HJ, Loomis D, McDonald MA, Argue RA, Wing S: A conceptual model of work and health disparities in the United States. Int J Health Serv 2006, 36(1):25-50.

27. Heymann SJ, Toomey S, Furstenberg F: Working parents: what factors are involved in their ability to take time off from work when their children are sick? Arch Pediatr Adolesc Med 1999, 153(8):870-874.

28. Busch SH, Barry CL, Vesgo SJ, Sindelar JL, Cullen MR: Effects of a cost-sharing exemption on use of preventive services at one large employer. Heal Aff 2006, 25:1529-1536.

29. Rowe JW, Brown-Stevenson T, Downey T, Newhouse JP: The effect of consumer-directed health plans on the use of preventive and chronic illness services. Heal Aff 2008, 27:113-120.

30. Wharam JF, Galbraith AA, Kleinman KP, Soumerai SB, Ross-Degnan D, Landon BE: Cancer screening before and after switching to a highdeductible health plan. Ann Intern Med 2008, 148(9):647-655.

31. Makuc DM, Breen N, Meissner HI, Vernon SW, Cohen A: Financial barriers to mammography: who pays out-of-pocket? J Womens Health 2007, 16(3):349-360

32. Trivedi AN, Rakowski W, Ayanian JZ: Effect of cost sharing on screening mammography in medicare health plans. N Engl J Med 2008, 358(4):375-383.

doi:10.1186/1471-2458-12-520

Cite this article as: Peipins et al:: The lack of paid sick leave as a barrier to cancer screening and medical care-seeking: results from the National Health Interview Survey. BMC Public Health 2012 12:520.

\section{Submit your next manuscript to BioMed Central and take full advantage of:}

- Convenient online submission

- Thorough peer review

- No space constraints or color figure charges

- Immediate publication on acceptance

- Inclusion in PubMed, CAS, Scopus and Google Scholar

- Research which is freely available for redistribution 